\title{
A governança metropolitana e o desafio da integração na lei $n^{\circ} 13.089 / 2015$
}

\author{
Metropolitan governance and the challenge of integration under \\ law 13,089/2015
}

Marcus Vinicius Gonçalves da Silva ${ }^{[0]}$, Amanda Cristina Pasqualini Peron ${ }^{[0]}$, Maria Lúcia Figueiredo Gomes de Meza ${ }^{[0]}$, Décio Estevão do Nascimento ${ }^{[0]}$, Cleiton Sacoman ${ }^{[b]}$

\footnotetext{
[a] Universidade Tecnológica Federal do Paraná (UTFPR), Curitiba, PR, Brasil

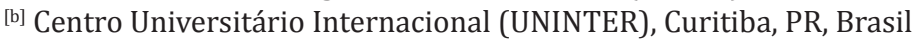

\section{Resumo}

A década de 1970 foi, para o Brasil, precursora no desenvolvimento das regiões metropolitanas. A partir da Constituição Federal de 1988, os Estados puderam, mediante lei complementar, instituir suas regiões metropolitanas, constituídas por agrupamentos de municípios que possuem fronteiras contíguas, culminando na criação de regiões caracterizadas por critérios múltiplos e diferenciados. Contudo, em janeiro de 2015, foi aprovado o Estatuto da Metrópole, com o objetivo de estabelecer diretrizes para o planejamento, a gestão e a implementação das funções públicas de interesses comuns em regiões metropolitanas e aglomerações urbanas. Este artigo, de natureza descritiva e baseada em dados bibliográficos, visa refletir sobre a implantação da Lei no $13.089 / 2015$, recente instrumento de governança aplicado às regiões metropolitanas, partindo da premissa de que a estrutura federativa existente não abarcou a institucionalidade dessas regiões. Concluiu-se que os instrumentos de integração nas regiões metropolitanas alinham-se a um processo contínuo na promoção de uma gestão metropolitana eficaz e baseada em responsabilidades mútuas.

Palavras-chave: Governança. Metrópole. Região metropolitana. Lei no 13.089/2015. Instrumento de integração.

\section{Abstract}

Metropolitan areas started to develop in Brazil during in the 1970s. The Federal Constitution of 1988 made it possible for the states, by means of a complementary law, to organize their metropolitan areas into clusters of municipalities with contiguous borders and this culminated in the creation of regions characterized by multiple and different criteria. However, the Statute of the Metropolis was approved in January 2015 with the purpose of establishing guidelines for the planning, management and implementation of public functions of common interest to metropolitan areas and urban agglomerations. This article, which is descriptive in nature

MVGS é administrador público, mestre em Planejamento e Governança Pública, e-mail: marvin.gsilva@gmail.com ACPP é advogada, mestre em Planejamento e Governança Pública, e-mail: amandapasqualini@gmail.com MLFGM é professora na Universidade Tecnológica Federal do Paraná, doutora em Desenvolvimento Econômico, e-mail: malumeza2@gmail.com

DEN é professor na Universidade Tecnológica Federal do Paraná; doutor em Ciências do Homem e Tecnologia, e-mail: decioen@gmail.com CS é advogado, mestrando em Direito, e-mail: cleiton.sacoman@terra.com.br 
and based on bibliographical data, aims to reflect on the implementation of the Law 13,089/2015, a recent governance tool applied to metropolitan areas, based on the premise that the existing federal structure has not yet incorporated the institutionality of these regions. We concluded that the instruments for integration of metropolitan areas are aligned with a continuous process of promoting effective metropolitan management based on mutual responsibilities.

Keywords: Governance. Metropolis. Metropolitan region. Law no 13,089/2015. Integration instrument.

\section{Introdução}

No Brasil, cabe ao Estado a definição dos requisitos para a criação de novos municípios. Essa possibilidade, advinda da Constituição Federal de 1988, deu vez e voz para um considerável aumento no número de municípios brasileiros, gerando diversidade e multiplicidade de critérios, que vão desde o número de habitantes e edificações até a criação de novos municípios por interesses políticos e eleitoreiros, por vezes sem condições financeiras de arcar com suas despesas, corroborando o aumento das desigualdades sociais. Nesse sentido, Tomio (2002, p. 63) aponta que “[...] em 1980, o número de municípios brasileiros era de 3.974, passando a ter após a CF/1988, 4.491 em 1990 e, 5.560 no ano de 2000".

Ainda que a presença da desigualdade e da segregação social como componentes do processo de desenvolvimento urbano nacional não se restrinja apenas às áreas metropolitanas, estas são as que concentram o ônus da estrutura desigual do país, uma vez que nelas se encontram um significativo agrupamento demográfico relacionado a uma densidade de relações sociais, econômicas, culturais, ambientais, entre outras.

Uma metrópole, geralmente, é caracterizada como determinado espaço que exerce influência cultural, social e econômica sobre um conjunto de cidades unidas geograficamente. Na prática, é um território integrado com escala de produção, distribuição e acumulação de riqueza e de reprodução social (Fresca, 2011).

Em contrapartida, a região metropolitana (IPEA, 2013), em termos institucionais, é caracterizada por uma fragmentação que consiste em critérios múltiplos e diferenciados, ou seja, o Estado, dentro de sua discricionariedade, cria, por intermédio da lei, esse conjunto de cidades, contudo não lhes assegura condições necessárias para que a funcionalidade dessa nova instituição seja plenamente realizável.

Diante dessa situação, emerge a necessidade de instrumentos e institucionalidades sistematizadas que possibilitem a prática de uma efetiva governança em áreas metropolitanas, a exemplo da recente Lei no 13.089, de 13 de janeiro de 2015.

Com base nessas premissas que cercam a governança metropolitana, esta pesquisa, de natureza descritiva e baseada em dados bibliográficos, procura envolver a Lei no 13.089/2015 nos seguintes questionamentos: desde sua publicação, quais instrumentos têm auxiliado a governança de regiões metropolitanas? Estes permitem solucionar os desafios que se fazem presentes nesses agrupamentos?

Assim, o presente trabalho estrutura-se com as seguintes perspectivas: reflexão acerca das transformações que ocorreram após os anos de 1970, na forma de organização e intervenção do Estado no espaço urbano e regional; abordagem histórica traçando a linha do tempo das áreas metropolitanas brasileiras da década de 1970 até o advento da Constituição de 1988; espaços metropolitanos e a necessidade das soluções conjuntas; e, por fim, análise da Lei no 13.089 , publicada em 13 de janeiro de 2015, que regulamenta o Estatuto da Metrópole.

\section{Os regimes espaciais brasileiros na década e pós-década de 1970}

Referir-se a regimes espaciais comporta a necessidade de reflexão acerca das transformações que ocorrem, após os anos de 1970, na forma de organização e intervenção do Estado no espaço urbano e regional. Para tanto, a presente seção trará uma abordagem histórica traçando a linha do tempo das áreas metropolitanas brasileiras da década de 1970 até o advento da Constituição de 1988. 


\section{A questão metropolitana e seus conceitos}

0 Brasil, de acordo com o estudo realizado em 2012 pelo Observatório das Metrópoles, possuía 59 unidades institucionalizadas, entre regiões metropolitanas e regiões integradas de desenvolvimento e aglomerações urbanas. Em 2015, o número totalizou 78, das quais cinco foram criadas anteriormente à vigência da Lei no 13.089, de 13 de janeiro 2015 (Ribeiro et al., 2015). Nos moldes fixados pelo Instituto Brasileiro de Geografia e Estatística (IBGE), o Brasil conta com 12 metrópoles (Ribeiro et al, 2015), apresentando divergência entre as características de definição adotadas pelas leis complementares estaduais, emanadas do poder atribuído pela Constituição Brasileira de 1988, em que cabe aos governos estaduais a instituição e o reconhecimento legal das regiões metropolitanas, possibilitando a integração, o planejamento e a execução de funções públicas de interesse comum, conforme reza a Carta Magna:

Art. $25[\ldots]$

$\S 3^{\circ}$. Os Estados poderão, mediante lei complementar, instituir regiões metropolitanas, aglomerações urbanas e microrregiões, constituídas por agrupamentos de municípios limítrofes, para integrar a organização, o planejamento e a execução de funções públicas de interesse comum. (Brasil, 1988).

Para compreender essa diferença de números e de caracterização tão distinta em um mesmo país, vale recorrer a alguns conceitos e princípios de composição utilizados no debate acadêmico, que engloba questões referentes à metrópole, região metropolitana e megalópole.

Desse modo, faz-se necessário definir e conceituar o que é metrópole e região metropolitana, para refletir sobre as transformações que ocorreram no Brasil após os anos de 1970 quanto à forma de organização e intervenção do Estado no espaço urbano e regional.

0 termo "metrópole" não é algo da modernidade ou imposto a partir da Revolução Industrial, mas proveniente da Grécia Antiga. Seu sentido estava relacionado à designação de cidade-mãe, a grande cidade detentora de funções das quais dependiam as demais. Assim, a metrópole estaria relacionada ao domínio de um território, à oferta de bens e serviços diferenciados a uma região (Di Méo, 2008).
Um dos primeiros estudiosos a tratar da complexidade urbana, indicando conceitos, foi o botânico Patrick Geddes no início do século XX, o qual propôs os termos "conurbação" e "megalópole", fato que o tornou nome de referência no que tange a assuntos e temas ligados ao urbanismo, à geografia e à sociologia. Seus conceitos apresentavam uma proposição da realidade urbana que pode ser ainda aplicável, caso sejam guardadas as proporções de tempo e espaço.

A experiência de Geddes, baseada na cidade de Londres do final do século XIX e início do XX, foi o fio condutor para reflexão acerca de como a cidade vai, pouco a pouco, absorvendo cidades menores, em uma dinâmica complexa, para a qual, à época, faltavam palavras que dessem conta das especificidades advindas dessa nova realidade de imprecisão entre os limites da cidade e do campo e entre as próprias cidades (Firkowski, 2013).

Destarte, por conurbação, Geddes entende essa

[...] nova forma de agrupamento demográfico, que já está, subconscientemente, desenvolvendo novas formas de agrupamento social, e, em seguida, de governo e administração bem definidos (Geddes, 1994 apud Firkowski, 2013, p. 24).

0 vocábulo, então, passou a aludir à complexa dinâmica da urbanização: o modo de vida das pessoas das áreas urbanas e formas de gestão e a necessidade de medidas conjuntas para a saúde, educação, assistência, enfim, da estrutura e constituição desses espaços.

De acordo com a estudiosa Olga Firkowski, o conceito absorve certa inexatidão advinda da tradução e, talvez, do fato de o Brasil, à época que o conceito foi introduzido, ser incipiente, sendo mais associado "[...] à junção de manchas urbanas de cidades diferentes que a um verdadeiro processo de constituição de uma cidade-região" (Firkowski, 2013, p. 23).

Ao evidenciar e situar a transição da metrópole moderna à contemporânea, utiliza-se o termo "conurbação" referindo-se à "[...] ação de reunir em um todo diversos núcleos e cidades pela unificação das suas malhas urbanas, respeitando uma hierarquia funcional" (Meyer, 2000, p. 5).

No dizer de Villaça, a proposta de Geddes, que chegou ao contexto brasileiro por volta dos anos de 1920, foi interpretada como "fusão de áreas urbanas", e o termo poderia ser utilizado em substituição aos de metrópole e região metropolitana, caracterizando-a 
como área metropolitana, a qual poderia melhor especificar a expansão dos núcleos e as contradições ocorridas entre essa dilatação espacial e a jurisdição do ente administrativo, residindo nesse fato a contradição "[...] entre a cidade como organismo físico e socioeconômico e a cidade do ponto de vista político-administrativo" (Villaça, 1998 apud Firkowski, 2013, p. 51).

Outro conceito também atribuído a Geddes é o de megalópole, em que o prefixo mega fora adaptado do grego para designar a grandeza, sobretudo do ponto de vista da grande concentração populacional, e a extensão da área, a exemplo de Chicago e Nova Iorque.

Já a região metropolitana pode ser considerada uma área composta de um conjunto de cidades contíguas e com integração socioeconômica a um município de grande porte, fenômeno conhecido, como já visto, por conurbação.

Vale considerar, nesses termos, que os conceitos estabelecidos por Geddes não possuem o mesmo conteúdo da atualidade, pois sua substância se modificou à medida que os processos históricos aconteceram, conforme destacado anteriormente. Dizendo de outro modo: o fato de existir certa complexidade em conceituar alguns termos usados para designar o processo de instauração de uma metrópole ou região metropolitana não impede de refletir sobre os mecanismos criados, a exemplo do que consta na Constituição e o que apregoa a Lei no 13.089/2015, para atender aos desafios impostos pelos grandes conglomerados de cidades e pessoas que se avolumam nas metrópoles, tópico que será discutido a seguir. Entretanto, será pertinente expor alguns dos marcos que diferenciaram questões relativas à divisão de espaços geográficos brasileiros.

Linha do tempo das áreas metropolitanas brasileiras

A inauguração de marcos legais, centrada em questões de divisão de espaços geográficos, surge no Brasil quase que especificamente no século XX. Contudo, a fundação das primeiras cidades brasileiras ocorreu após a Constituição de 1824, a qual acenava que a instituição de cidades era direito da Coroa, e a das vilas, proveniente de ações dos donatários, capitães e governadores (Brasil, 1824).
Em 1938, entrou em vigor o Decreto-Lei no 311, que explicitava uma divisão territorial do país diversa da anterior. Nesse sentido, as sedes municipais tornaramse cidades, e as sedes dos distritos passaram a vilas. Aos municípios caberia o papel de estabelecer o mapa de seu território, demarcando as áreas urbanas, com base no art. 12 da referida lei: "Nenhum município se instalará sem que o quadro urbano da sede abranja no mínimo duzentas moradias" (Brasil, 1938).

A Lei Complementar $\mathrm{n}$ ㅇ 1 , de 9 de novembro de 1967, ampliou o enfoque dado anteriormente e estabeleceu que:

Art. 2o - Nenhum Município será criado sem a verificação da existência, na respectiva área territorial, dos seguintes requisitos:

I - população estimada, superior a 10.000 (dez mil) habitantes ou não inferior a 5 (cinco) milésimos da existente no Estado;

II - eleitorado não inferior a 10\% (dez por cento) da população;

III - centro urbano já constituído, com número de casas superior a 200 (duzentas);

IV - arrecadação, no último exercício, de 5 (cinco) milésimos da receita estadual de impostos. (Brasil, 1967).

Por Ato Complementar, também passou a ser exigida a prévia autorização do presidente da República. Sob essa legislação, nenhum novo município foi criado (Barros \& Lago, 2015).

Com a Constituição Federal de 1988, foram alargadas as responsabilidades dos Estados, uma vez que, em seu art. 18, passou a delegar, aos entes federados, a definição dos requisitos para a criação de novos municípios, atribuição que gerou grande diversidade e multiplicidade de critérios, que vão desde o número de habitantes e edificações até interesses políticos. Esse fato "[...] ampliou o número de municípios, passando de 3.992, na década de 1980, para 5.507, em 2000, e 5.565, em 2010" (Firkowski, 2013, p. 32).

Infere-se que, das mudanças estabelecidas, decorreram disparidades entre os critérios instituídos por cada Estado, e um número muito grande de municípios foi criado, na maior parte das vezes, sem condições financeiras de arcar com suas despesas. 
A Constituição de 1988 inseriu também a possibilidade de os Estados criarem regiões metropolitanas, aglomerações urbanas e microrregiões, igualmente sem uma definição mais homogênea de critérios, resultando "[...] na mesma perspectiva dos municípios, em discrepâncias estaduais flagrantes e na ausência de critérios que tenham o conjunto federativo como horizonte" (Firkowski, 2013, p. 33).

Quanto à divisão entre as metrópoles e as regiões metropolitanas, significa dizer que passou a existir uma separação advinda do fato de que a forma como surge uma região metropolitana enseja uma institucionalização, diversa da metrópole, resultante de um processo socioespacial. Assim, a legislação brasileira maior, ao dispor de escassas metodologias e critérios para caracterizar as regiões metropolitanas, incorre em fragilidades, pondo em xeque o próprio significado dessa institucionalização, existindo

[...] por um lado, uma instituição de ordem jurídico-institucional, baseada em motivações múltiplas - nem sempre explícitas -, que sugere a intenção de tratar, intervir ou gerir esta nova territorialidade, a qual pode ou não, integral ou parcialmente, corresponder a um espaço metropolitano resultante de um processo socioespacial. (Costa, 2013, p. 324).

Essa carência de contornos fora evidenciada por Hotz (2000), ao revelar que ela já era apresentada na pauta dos debates que antecederam a elaboração da Constituição de 1988, ficando desvendado o esgotamento dos formatos institucionais disponíveis para a organização regional em âmbito metropolitano no país, bem como a necessidade de substituí-los.

Em suas formulações mais gerais, a Constituição de 1988, embora indiretamente, favoreceu a possibilidade da organização regional no país, da qual se destaca a alçada dos municípios a entes federados, podendo organizar suas leis orgânicas com a divisão de competências entre os três níveis de governo e matérias tratadas de forma concorrente e comum. Ainda reconheceu o Estado como agente normativo e regulador da atividade econômica, efetuando as funções de fiscalização, incentivo e planejamento dos setores públicos e privados na forma prevista no art. 174 da Carta Magna (Brasil, 1988).

Ao tratar das questões metropolitanas brasileiras e seus desafios, especificamente os relacionados ao desenvolvimento urbano, a Constituição Federal de 1988, em seus arts. 21, inciso XX, 24, inciso I, e 30, inciso VIII, delega ao âmbito da administração municipal a responsabilidade da política urbana, cabendo a esta a observância das diretrizes gerais fixadas em lei (Brasil, 1988; Hotz, 2000). Finda, assim, a hegemonia do governo estadual em detrimento dos governos locais (Azevedo \& Mares Guia, 2011).

Nesse aspecto, Balbim et al (2011) analisam os efeitos da Constituição de 1988 e afirmam que a valorização concomitante do poder municipal e, principalmente, as falhas de articulação entre as três esferas de governo expressaram problemas do federalismo brasileiro; então, para a gestão metropolitana, restou um processo de enfraquecimento e de desarticulação.

Como reflexo, há a criação de regiões metropolitanas caracterizadas por critérios múltiplos e diferenciados, especialmente quanto à funcionalidade e à institucionalização, necessitando, então, de dispositivos legais na busca de sanar esse déficit, o que segue exposto no próximo tópico.

\section{O Estatuto da Metrópole}

As condições de vida da população, marcadas, muitas vezes, por carências de serviços urbanos, de educação, de saúde, e, ao mesmo tempo, geradoras de demandas que não correspondem aos limites jurisdicionais a que se referem, trouxeram a necessidade das metrópoles: território integrado com escala de produção, distribuição, acumulação de riqueza e de reprodução social.

Nesse processo, a dificuldade a ser superada é a de transformar a metrópole funcional em institucional (Lefèvre, 2009). A metrópole funcional é vista como um território integrado com escala de produção, distribuição, acumulação de riqueza e de reprodução social. No entanto, ela é estabelecida de maneira inadequada e descompassada, originando um problema de legitimidade da prática de governança metropolitana no Brasil (Borges, 2013).

O objetivo constitui-se em instrumentos para enfrentar os problemas concretos presentes nesses territórios, uma vez que essas novas conformações territoriais apresentaram-se desprovidas de competências para atender aos próprios pleitos. É nesse contexto que se apresenta o Estatuto da Metrópole, aprovado pela Lei no 13.089/2015, objeto de análise na seção seguinte. 


\section{novo Estatuto da Metrópole}

Do ano de 2004, emergem critérios que foram fixados no Projeto de Lei no 3.460 (Estatuto da Metrópole, Brasil, 2004), o qual pautava seus objetivos em um conjunto de instrumentos regulatórios à questão metropolitana no país, regulamentando a ação dos entes federados nos territórios em que as funções públicas de interesse comum devessem ser compartilhadas (Rodrigues, 2013).

No 37ํㅡㄹ Encontro Nacional de Sindicatos de Arquitetos, em Goiânia, e na 5 a Conferência Nacional das Cidades, que ocorreu em 2013, na cidade de Brasília, Zezéu Ribeiro, deputado e relator do referido projeto de lei, afirmou que a aprovação do Estatuto da Metrópole possuía como função

[...] compatibilizar projetos estaduais e municipais e trazer mais eficiência aos serviços prestados, como a coleta de lixo, transporte público, entre outros. A ideia é trabalhar com marcos regulatórios para a questão das metrópoles no Brasil, pois no processo constituinte nós avançamos pouco nesse sentido, então é necessário avançar muito mais, articulando as diversas intervenções que devem ser feitas nas cidades que se caracterizam como áreas metropolitanas, através da sistematização de serviços comuns, como a questão da coleta do lixo, no transporte e no saneamento como um todo, para que se tenha uma vida melhor em todas as cidades. (Rizzo, 2013, p. 1).

Observou-se que a trajetória entre o texto e a sua aprovação durou mais de uma década, e, no dia 13 de janeiro de 2015, entrou em vigor a Lei $\mathrm{n}$ - 13.089. A recente lei estabeleceu fundamentos e diretrizes para a gestão urbana compartilhada. 0 art. $1^{\circ}$, detalhadamente, aclara esses objetivos trazidos na inovação legislativa.

Art. 1 o Esta Lei, denominada Estatuto da Metrópole, estabelece diretrizes gerais para o planejamento, a gestão e a execução das funções públicas de interesse comum em regiões metropolitanas e em aglomerações urbanas instituídas pelos Estados, normas gerais sobre o plano de desenvolvimento urbano integrado e outros instrumentos de governança, e critérios para o apoio da União a ações que envolvam governança interfederativa no campo do desenvolvimento urbano interfederativa, e critérios para o apoio da União a ações que envolvam governança interfederativa no campo do desenvolvimento urbano [...]. (Brasil, 2015a).

A partir dos objetivos e das diretrizes fixadas, a lei dá abertura ao seu segundo artigo, trazendo conceitos que nortearão os atos nela pautados. É nesse contexto que o projeto de lei original sofreu inúmeras críticas, desencadeando um processo de descrédito de seu texto e ensejando sua revisão integral.

Por essa versão, a primeira [Região Metropolitana] deveria ostentar um núcleo central com, no mínimo, 5\% (cinco por cento) da população do País (9.537.789 habitantes em 2010) e, para a segunda, exigia-se, no mínimo, 2,5\% da população (4.768.895 habitantes) (art. 6, I, a e b). Exceto a RM polarizada por São Paulo, não havia na época, nem existe atualmente, qualquer outra aglomeração com tal característica; da mesma forma, só a unidade polarizada pelo Rio de Janeiro poderia tornar-se uma aglomeração urbana. (Moura \& Hoshino, 2015, p. 2).

A tais inconsistências somaram-se outras inadequações, como a abrangência exacerbada de alguns conteúdos e o tratamento simplista de outros, que evidenciaram a necessidade de se rever cada artigo do projeto proposto. Esse emaranhado desemboca no substitutivo apresentado, fruto de árduo debate, com encaminhamento à sanção presidencial, enraizado em outras tantas modificações do texto e aposição de veto presidencial.

Vale ressaltar que uma das situações incongruentes refere-se aos arts. 17 e 18 inseridos no capítulo V, os quais abarcavam a previsão de criação e existência do Fundo do Estatuto da Metrópole e possuíam a seguinte redação:

Art. 17. Fica instituído o Fundo Nacional de Desenvolvimento Urbano Integrado - FNDUI, de natureza contábil e financeira, com a finalidade de captar recursos financeiros e apoiar ações de governança interfederativa em regiões metropolitanas e em aglomerações urbanas, nas microrregiões e cidades referidas no $\S 1^{\mathrm{o}}$ do art. $1^{\mathrm{o}}$ desta Lei e em consórcios públicos constituídos para atuação em funções públicas de interesse comum no campo do desenvolvimento urbano. 
Art. 18. Constituem recursos do FNDUI:

I - recursos orçamentários da União a ele destinados;

II - recursos decorrentes do rateio de custos com Estados e Municípios, referentes à prestação de serviços e realização de obras afetas às funções públicas de interesse comum;

III - contribuições e doações de pessoas físicas ou jurídicas;

IV - contribuições de entidades e organismos de cooperação nacionais ou internacionais;

$\mathrm{V}$ - receitas operacionais e patrimoniais de operações realizadas com recursos do Fundo; e,

VI - outros recursos que lhe vierem a ser destinados na forma da lei.

§ 1ํA A aplicação dos recursos do FNDUI será supervisionada por um conselho deliberativo, com a participação da União, dos Estados e dos Municípios, bem como de representantes da sociedade civil.

$\S$ 2으 0 regulamento disporá sobre o órgão gestor do FNDUI e sobre o grupo de assessoramento técnico ao Fundo.

$\S$ 3ํㅜ Fica vedada a utilização dos recursos do FNDUI para o pagamento de dívidas e coberturas de déficits fiscais de órgãos e entidades de qualquer esfera de governo.

$\S 4^{\circ}$ Os recursos referidos no inciso II do caput deste artigo, se alocados por Estado, somente podem ser aplicados na própria unidade da Federação e, se alocados por Município ou pelo Distrito Federal, na própria região metropolitana ou aglomeração urbana a que ele pertencer. (Brasil, 2015a).

Quando do encaminhamento à sanção presidencial, tal proposta foi objeto de aposição de veto com a justificativa de que fundos cristalizam a vinculação a finalidades específicas, prejudicando a dinâmica de prioridades políticas, e essas figuras não asseguram a eficiência na gestão dos recursos públicos. Ainda, não obstante as alegações já transcritas, o veto foi complementado pela insurgência de que as previsões do Estatuto da Metrópole podiam ser executadas regularmente por meio de dotações orçamentárias consignadas no Orçamento Geral da União vinculadas às programações relativas ao apoio da União ao Desenvolvimento Urbano Integrado (Brasil, 2015b).

Arrisca-se a dizer que a medida parece afastar a atuação direta do controle social e da transparência, pois representantes da sociedade civil teriam assento no conselho deliberativo, destinado a supervisionar o fundo, o que se apresenta mais distante com a inexistência do fundo e a utilização do orçamento geral.

Já os Estados e municípios ficaram eximidos da obrigatoriedade de destinar recursos próprios ao fundo. Vê-se quase que inimaginável, ou melhor, difícil de ser digerida, qualquer determinação que viesse a obrigá-los a aplicar recursos em um fundo nacional em detrimento do uso direto em suas unidades territoriais, ainda que, posteriormente, houvesse a intenção de retorno.

Além dos já citados arts. 17 e 18, o veto também abrangeu outros dispositivos do projeto encaminhado para sanções, referentes ao inciso II do $\S 1^{\circ}$ do art. $1^{\circ}$ e ao art. 19. A justificativa para tal procedimento encontra berço na seguinte argumentação "[...] por inconstitucionalidade e contrariedade ao interesse público", inseridas na Mensagem no 13/2015 (Brasil, 2015b).

Observou-se que o trânsito pelos trâmites legais do projeto do Estatuto da Metrópole foi polêmico, passando por arquivamento, emendas, um substitutivo, aprovação pelo Congresso Nacional e veto presidencial, ou seja, uma longa trajetória até a sua versão final, a lei propriamente dita.

\section{Destaques da nova lei: conceitos e instrumentos}

A Lei $\mathrm{n}^{0}$ 13.089/2015 explicita a que veio, avocando o conceito das regiões metropolitanas e aglomerados urbanos. Estabelece as suas aplicações e apadrinha as microrregiões instituídas pelos Estados. Em seu art. $2^{\circ}$, comporta um relevante arcabouço conceitual sobre: aglomeração urbana, metrópole, região metropolitana, função pública de interesse comum, plano de desenvolvimento urbano integrado, gestão plena e governança interfederativa, de forma que 
esses institutos, além de teóricos, recebem definição legal e passam a ser jurídicos.

o Estatuto, no intuito de erradicar ou, pelo menos, amenizar os percalços ocasionados por problemas estruturais traduzidos em sequenciais crises da mobilidade, saneamento, habitação, resíduos sólidos, e que se associam às fragilidades do planejamento e da gestão metropolitana, consigna que as leis complementares estaduais, ao instituírem as regiões metropolitanas e as aglomerações urbanas, comportarão em seus conteúdos as funções públicas de interesse comum que justificam a medida, a estrutura de governança interfederativa e os meios de controle social da organização, do planejamento e da execução das funções públicas - art. 5ㅜㅡ, incisos I a IV do diploma legal -, cada qual com conceito assim entendido:

Art. $2^{\circ}[\ldots]$

II - função pública de interesse comum: política pública ou ação nela inserida cuja realização por parte de um Município, isoladamente, seja inviável ou cause impacto em Municípios limítrofes;

III - gestão plena: condição de região metropolitana ou de aglomeração urbana que possui:

a) formalização e delimitação mediante lei complementar estadual;

b) estrutura de governança interfederativa própria, nos termos do art. $8^{\circ}$ desta Lei; e

c) plano de desenvolvimento urbano integrado aprovado mediante lei estadual;

IV - governança interfederativa: compartilhamento de responsabilidades e ações entre entes da Federação em termos de organização, planejamento e execução de funções públicas de interesse comum [...]. (Brasil, 2015a).

Nesse contexto, a obrigatoriedade relatada decorre dos previstos legais do Capítulo II, abrindo espaço para os comentários de Moura \& Hoshino (2015, p. 5) de que:

[...] a exigência de embasar em critérios técnicos a delimitação territorial e o rol de funções comuns eleitas como prioritárias para cada unidade (art. 5으, $\$ 1^{\circ}$ ) representa um avanço nada desprezível, ao viabilizar o controle (da sociedade como dos órgãos de fiscalização externa) sobre a motivação dos atos das autoridades políticas, reduzindo o espaço da pura discricionariedade. Do ponto de vista jurídico, a exposição de motivos dos respectivos projetos de lei complementar seria o espaço ideal para sistematizar esse conjunto de estudos e diagnósticos em que a proposta se sustenta.

A nova lei, pelo menos aparentemente, afasta o municipalismo das políticas setoriais, instituindo o planejamento e a gerência em nível regional ou metropolitano, por atendimento à previsão do art. 10, §3ํo (Brasil, 2015a). Ainda deixa como determinação a necessidade de que os municípios compatibilizem seus Planos Diretores com as novas diretrizes do plano de desenvolvimento urbano integrado da unidade territorial urbana. A partir desse afastamento, surge uma dúvida: se as políticas setoriais são mais eficientes e inclusivas se fundadas no desenvolvimento urbano integrado.

Em continuidade à análise, replica-se a ideia trazida por Moura \& Hoshino (2015, p. 6):

O cenário avulta ainda mais espinhoso nas hipóteses de prestação por delegação. Os serviços caracterizados como FPIC se submeterão a novo regime jurídico, não mais passível de concessão fragmentada, o que, espera-se, impactará na sua modelagem administrativo-financeira e se refletirá na abertura de novas licitações. 0 impasse atual em torno das responsabilidades sobre a Rede Integrada de Transportes de Curitiba (mormente no que tange ao Lote 4, justamente o do transporte metropolitano) é sintomático dessa lacuna de regulação.

O impasse gerador de demora na prestação adequada do serviço público deixa nome e endereço dos prejudicados: os cidadãos dessa região metropolitana.

Para atingir seus objetivos, o Estatuto da Metrópole enfatiza a prevalência do interesse comum sobre o local e consigna como diretrizes as já enumeradas no Estatuto da Cidade (Brasil, 2001), reforçando a implantação de processo permanente e compartilhado de planejamento e de tomada de decisão, observando o imperativo de gestão democrática das cidades.

Para tanto, adota estratégias como: 
I - implantação de processo permanente e compartilhado de planejamento e de tomada de decisão quanto ao desenvolvimento urbano e às políticas setoriais afetas às funções públicas de interesse comum;

II - estabelecimento de meios compartilhados de organização administrativa das funções públicas de interesse comum;

III - estabelecimento de sistema integrado de alocação de recursos e de prestação de contas;

IV - execução compartilhada das funções públicas de interesse comum, mediante rateio de custos previamente pactuado no âmbito da estrutura de governança interfederativa;

V-participação de representantes da sociedade civil nos processos de planejamento e de tomada de decisão, no acompanhamento da prestação de serviços e na realização de obras afetas às funções públicas de interesse comum;

VI - compatibilização dos planos plurianuais, leis de diretrizes orçamentárias e orçamentos anuais dos entes envolvidos na governança interfederativa;

VII - compensação por serviços ambientais ou outros serviços prestados pelo Município à unidade territorial urbana, na forma da lei e dos acordos firmados no âmbito da estrutura de governança interfederativa.

Parágrafo único. Na aplicação das diretrizes estabelecidas neste artigo, devem ser consideradas as especificidades dos Municípios integrantes da unidade territorial urbana quanto à população, à renda, ao território e às características ambientais. (Brasil, 2001).

Percebe-se ainda que o art. 8º da Lei no 13.089/2015 comporta a estrutura para a governança interfederativa das regiões metropolitanas e das aglomerações urbanas, enumerando: i) uma instância executiva; ii) uma instância colegiada deliberativa com representação da sociedade civil; iii) uma organização pública com funções técnico-consultivas; e iv) um sistema integrado de alocação de recursos e de prestação de contas.
A inovação é dotada de boas intenções, mas traz à tona uma discussão já ventilada pela doutrina, qual seja: a de dotar as personalidades do Estatuto da Metrópole de atributos político-administrativos, o que a Constituição Federal já deveria tê-lo feito desde 1988, quando alçou os municípios a referido patamar (Klink, 2013; Rodrigues, 2013).

Assim, problemáticas, como a de que os orçamentos são municipais e os problemas ultrapassam essas fronteiras, estariam superados, mas a Constituição tornou-se impedimento para superar essa barreira. Nesse viés, o Estatuto, por sua vez, com o objetivo de suplantar esses problemas, cria instrumentos de governança interfederativa - o compartilhamento de responsabilidades e ações entre entes da federação em termos de organização, planejamento e execução de funções públicas de interesse comum, nos termos do art. 2o ${ }^{\circ}$, inciso IV, do Estatuto (Brasil, 2015a). Em outras palavras, assumem-se responsabilidades mútuas e colocadas em prática por dez instrumentos dispostos no art. 9o (Brasil, 2015a).

Art. $9^{\circ}$ Sem prejuízo da lista apresentada no art. $4^{\circ}$ da Lei $n^{\circ} 10.257$, de 10 de julho 2001, no desenvolvimento urbano integrado de regiões metropolitanas e de aglomerações urbanas serão utilizados, entre outros, os seguintes instrumentos:

I - plano de desenvolvimento urbano integrado;

II - planos setoriais interfederativos;

III - fundos públicos;

IV - operações urbanas consorciadas interfederativas;

V - zonas para aplicação compartilhada dos instrumentos urbanísticos previstos na Lei $\mathrm{n}^{\circ}$ 10.257, de 10 de julho de 2001;

VI - consórcios públicos, observada a Lei ${ }^{0} 11.107$, de 6 de abril de 2005;

II - convênios de cooperação;

VIII - contratos de gestão;

IX - compensação por serviços ambientais ou outros serviços prestados pelo Município à 
unidade territorial urbana, conforme o inciso VII do caput do art. $7^{\circ}$ desta Lei;

X-parcerias público-privadas interfederativas.

Dos instrumentos propostos para auxiliar a governança das regiões metropolitanas, a lei dedica especial atenção ao plano de desenvolvimento urbano integrado (art. 9o, inciso I), que estabelece as diretrizes para o desenvolvimento urbano, inclusive impondo penalidades em caso de sua não elaboração (art. 21).

O plano é o instrumento que dará suporte ao crescimento dos municípios pertencentes à mesma região metropolitana ou ao aglomerado urbano e que contemplará:

Art. $12[\ldots]$

$\S 1 \stackrel{0}{\cdots}$

I - as diretrizes para as funções públicas de interesse comum, incluindo projetos estratégicos e ações prioritárias para investimentos;

II - o macrozoneamento da unidade territorial urbana;

III - as diretrizes quanto à articulação dos Municípios no parcelamento, uso e ocupação no solo urbano;

IV - as diretrizes quanto à articulação intersetorial das políticas públicas afetas à unidade territorial urbana;

V - a delimitação das áreas com restrições à urbanização visando à proteção do patrimônio ambiental ou cultural, bem como das áreas sujeitas a controle especial pelo risco de desastres naturais, se existirem; e,

VI - o sistema de acompanhamento e controle de suas disposições. (Brasil, 2015a).

Há de se considerar que o referido plano possui caráter complementar ao Plano Diretor. No entender de Moura \& Hoshino (2015, p. 9), a existência desse plano de desenvolvimento integrado

[...] configura condição sine qua non para o apoio da União às ações de desenvolvimento urbano integrado (Capítulo V), com realce para as iniciativas dos Estados e dos Municípios voltadas à governança interfederativa (art. 13). Nesse caso, será exigido que a unidade territorial urbana possua gestão plena, nos termos da lei, que pressupõe: a) formalização e delimitação mediante lei complementar estadual; b) estrutura de governança interfederativa própria; e c) plano de desenvolvimento urbano integrado aprovado. (art. 2, III).

A exemplo do que já praticado no Estatuto da Cidade (Brasil, 2001), o plano de desenvolvimento integrado deverá conter a participação social, promovendo de forma contínua a interlocução entre os representantes das esferas de governo e a sociedade civil.

A tarefa traduz-se árdua, pois, como bem destacado por Balbim et al. (2011) há falhas de articulação entre as três esferas de governo, enfraquecimento e desarticulação a gestão metropolitana no Brasil, além da ausência de um modelo acabado, ou sob único formato (Garson, 2009).

Da análise do instrumento legal, entre emendas e substituto, observa-se que o Estatuto da Metrópole preservou a essência dos objetivos trazidos no texto original, dispondo sobre: instituir regiões metropolitanas e aglomerações urbanas; moldar a governança interfederativa dessas unidades; fornecer os instrumentos de desenvolvimento urbano integrado; e garantir o apoio da União para sua implementação. Quanto ao Fundo Nacional de Desenvolvimento Urbano Integrado, o desejo de realizá-lo chegou às vias de tornar-se realidade, no entanto foi ceifado pelo veto presidencial.

\section{Considerações finais}

As regiões metropolitanas, que, na prática, comportam um território integrado com escala de produção, de distribuição e acumulação de riqueza e de reprodução social, são de inegável importância para um país. No Brasil, a Constituição de 1988 delegou aos Estados autonomia na determinação de critérios para a criação de novos municípios. Esse fato ampliou significativamente o número de municípios, surgindo, dessa forma, regiões metropolitanas com frágil potência econômica, revelando um esgotamento dos formatos institucionais disponíveis para a organização regional em âmbito metropolitano, bem como a necessidade de substituí-los. 
Nesse processo, a dificuldade a ser superada é a de transformar a metrópole funcional em institucional, constituindo instrumentos para enfrentar os problemas concretos presentes nesses territórios, uma vez que essas novas conformações territoriais apresentaram-se desprovidas de competências para atender aos próprios pleitos.

Assim, no intuito de corroborar o desenvolvimento desses espaços caracterizados pela aglomeração urbana, surgem novos dispositivos legais, instrumentos que auxiliam na governança dessas regiões metropolitanas, os quais ganham visibilidade com a criação da Lei no 13.089 , de 13 de janeiro de 2015.

Desse modo, o Estatuto das Metrópoles possui o escopo de mitigar os problemas, ao buscar a retomada do controle do crescimento dessas metrópoles, a partir de responsabilidades mútuas, afastando o municipalismo das políticas setoriais, instituindo o planejamento e a gerência em nível regional ou metropolitano, em atendimento à previsão contida

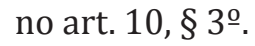

Os instrumentos disponibilizados para o alcance da governança interfederativa dessas unidades vieram dispostos em dez instrumentos descritos no art. 9o e expressam o auxílio na promoção de uma gestão metropolitana baseada em responsabilidades mútuas. Assim, busca-se aproximar a metrópole funcional da metrópole institucional, com o objetivo de dar operacionalidade a esta e eliminar a contradição entre a cidade como organismo físico e socioeconômico e a cidade do ponto de vista político-administrativo.

Em continuidade à problemática exposta no início deste estudo, infere-se que seja precoce descrever resultados e conclusões se os instrumentos propostos permitem solucionar os desafios dos municípios que compõem a unidade territorial urbana. Presume-se que a constatação dessa inquietude somente poderá ser aferida quando os municípios interfederados revisarem seus planos de desenvolvimento urbano integrado de região metropolitana. Nesse sentido, surge uma oportunidade para estudos futuros.

Observou-se ainda que os trâmites legais da Lei no 13.089/2015, em uma análise além da polêmica do arquivamento, das emendas, do substitutivo e do veto, preservaram a essência dos objetivos trazidos no texto original do Projeto de Lei no 3.460 , dispondo sobre: instituir regiões metropolitanas e aglomerações urbanas; moldar a governança interfederativa dessas unidades; fornecer os instrumentos de desenvolvimento urbano integrado; e garantir o apoio da União para sua implementação.

Por fim, leis são escritas por pessoas para pessoas, e os impasses que se revelam na criação de algumas têm alvo certo: os cidadãos das zonas rurais ou urbanas, das metrópoles ou das regiões metropolitanas brasileiras.

\section{Referências}

Azevedo, S., \& Mares Guia, V. R. (2011). Governança metropolitana e reforma do Estado: o caso de Belo Horizonte. Revista Brasileira de Estudos Urbanos e Regionais, 3, 131-144.

Balbim, R. N., Becher, M. F., Costa, M. A., \& Matteo, M. (2011). Desafios contemporâneos na gestão das regiões metropolitanas. Revista Paranaense de Desenvolvimento, 120, 149-176.

Barros, C. E., \& Lago, P. L. S. G. (2015). A força normativa da constituição e os municípios após a Emenda 15, de 1996: prenúncio de tensão entre legislativo e judiciário? Brasília: Senado. Recuperado em 11 agosto de 2015, de https://www12.senado.leg.br/publicacoes/estudoslegislativos/tipos-de-estudos/outras-publicacoes/ volume-ii-constituicao-de-1988-o-brasil-20-anos-depois.o-exercicio-da-politica/a-forca-normativa-da-constituicaoe-os-municipios-apos-a-emenda-15-de-1996-prenunciode-tensao-entre-legislativo-e-judiciario

Borges, W. A. (2013). Gestão Metropolitana: sua construção a partir de duas experiências de associativismo territorial na Região Metropolitana de Curitiba (Tese de doutorado). Fundação Getulio Vargas, São Paulo. Recuperado em 10 de janeiro de 2017, de http://bibliotecadigital.fgv.br/ dspace/handle/10438/10786

Brasil. (1824, 25 de março). Carta de Lei de 25 de março de 1824. Constituição Politica do Imperio do Brazil. Brasília: CLBR. Recuperado em 22 de setembro de 2015, de http://www.planalto.gov.br/ccivil_03/constituicao/ constituicao24.htm

Brasil. (1938, 2 de março). Decreto-Lei no 311, de 2 de março de 1938. Dispõe sobre a divisão territorial do país, e dá outras providências. Brasília: Diário Oficial da União. Recuperado em 20 de setembro de 2015, de http://www2. camara.leg.br/legin/fed/declei/1930-1939/decreto-lei311-2-marco-1938-351501-publicacaooriginal-1-pe.html 
Brasil. (1967, 9 de novembro). Lei Complementar no 1, de 9 de novembro de 1967. Estabelece os requisitos mínimos de população e renda pública e a forma de consulta prévia as populações locais para a criação de novos municípios, $e$ dá outras providências. Brasília: Diário Oficial da União. Recuperado em 25 de setembro de 2015, de http://www. planalto.gov.br/ccivil_03/leis/LCP/Lcp01.htm

Brasil. (1988, 5 de outubro). Constituição da República Federativa do Brasil. Brasília: Diário Oficial da União. Recuperado em 9 de setembro de 2015, de http://www. planalto.gov.br/ccivil_03/Constituicao/Constituicao.htm

Brasil. (2001, 10 de julho). Lei no 10.527, de 10 de julho de 2001. Estabelece diretrizes gerais da política urbana e dá outras providências. Brasília: Diário Oficial da União. Recuperado em 27 de setembro de 2015, de http://www.planalto.gov.br/ccivil_03/leis/LEIS_2001/ L10257.htm

Brasil. (2004, 5 de maio). Projeto de Lei no 3.460, de 5 de maio de 2004. Cria o Estatuto da Metrópole. Câmara dos Deputados. Recuperado em 22 de setembro de 2015, de http://www.camara.gov.br/proposicoesWeb/fichadetra mitacao?idProposicao $=251503$

Brasil. (2015a, 12 de janeiro). Lei no 13.089, de 12 de janeiro de 2015. Institui o Estatuto da Metrópole, altera a Lei $n^{\circ}$ 10.257, de julho, 2001 e dá outras providencias. Brasília: Diário Oficial da União. Recuperado em 10 de setembro de 2015, de http://www.planalto.gov.br/ ccivil_03/_Ato2015-2018/2015/Lei/L13089.htm

Brasil (2015b, 13 de janeiro). Mensagem no 13, de 12 de janeiro de 2015. Brasília: Diário Oficial da União. Recuperado em 28 de setembro de 2015, de http:// www.planalto.gov.br/CCIVIL_03/_Ato2015-2018/2015/ Msg/VEP-13.htm

Costa, M. A. (2013). Quarenta Anos de Regiões Metropolitanas no Brasil: um breve balanço exploratório. In M. A. Costa, \& T. L. Tsukumo (Ed.), 40 anos de regiões metropolitanas no Brasil. Brasília: IPEA. Recuperado em 26 de setembro de 2015, de http://www.ipea.gov.br/portal/index. php?option=com_content\&view=article $\&$ id $=19647$

Di Méo, G. (2008). Introdução ao debate sobre a metropolização. Confins, (4), 2-11. Recuperado em 27 de setembro de 2015, de https://confins.revues. org/5433?lang=pt
Firkowski, O. L. C. F. (2013). Metrópoles e regiões metropolitanas no Brasil: conciliação ou divórcio? In B. A. Furtado, C. Krause, \& K. C. B. França (Eds.), Território metropolitano, políticas municipais: por soluções conjuntas de problemas urbanos no âmbito metropolitano (pp. 2251). Brasília: IPEA.

Fresca, T. M. (2011). Uma discussão sobre o conceito de Metrópole. Revista da ANPEGE, 7(8), 31-52. http://dx.doi. org/10.5418/RA2011.0708.0003.

Garson, S. (2009). Regiões metropolitanas: por que não cooperam? Rio de Janeiro: Letra Capital.

Hotz, E. F. (2000). A Organização metropolitana pósconstituição de 1988. São Paulo em Perspectiva, 14(4), 91-98. http://dx.doi.org/10.1590/S0102-88392000000400010.

Instituto de Pesquisa Aplicada - IPEA. (2013). 40 anos de regiões metropolitanas no Brasil.. Brasília: IPEA. 336 p.

Klink, J. (2013). Por que as regiões metropolitanas continuam tão ingovernáveis? Problematizando a reestruturação e o reescalonamento do estado social desenvolvimentista em espaços metropolitanos. In B. A. Furtado, C. Krause, \& K. C. B. França (Eds.), Território metropolitano, políticas municipais: por soluções conjuntas de problemas urbanos no âmbito metropolitano (p. 85115). Brasília: IPEA.

Lefèvre, C. (2009). Governar as metrópoles: questões, desafios e limitações para a constituição de novos territórios políticos. Cadernos Metrópole, 11(22), 299-317.

Meyer, R. M. P. (2000). Atributos da metrópole moderna. São Paulo em Perspectiva, 14(4), 3-9. http://dx.doi. org/10.1590/S0102-88392000000400002.

Moura, R., \& Hoshino, T. A. P. (2015). Estatuto da metrópole: enfim, aprovado! Mas o que oferece à metropolização brasileira? Rio de Janeiro: Observatório das Metrópoles. Recuperado em 26 de setembro de 2015, de http://www. observatoriodasmetropoles.net/download/estatuto_ metropole_artigo_rosa.pdf

Ribeiro, L. C. Q., Santos, O. A., Jr., \& Rodrigues, J. M. (2015). Estatuto da Metrópole: o que esperar? Avanços, limites e desafios. Rio de Janeiro: Observatório das Metrópoles. Recuperado em 22 de setembro de 2015, de www.observatoriodasmetropoles.net/index.php ?option=comnk2\&view=item\&id $=1148 \% 3$ Aestatu 
to-da-metr $\%$ C3\%B3pole-avan $\%$ C3\%A7 os-limites-edesafios\&Itemid $=180$

Rizzo, G. (2013). O Estatuto das Metrópoles e as regiões metropolitanas. Brasília: CAU/BR. Recuperado em 27 de setembro de 2015, de http://www.caubr.gov.br/?p=17650

Rodrigues, A. L. (2013). Ingovernabilidade metropolitana e segregação socioespacial: receita para a explosão da violência. In B. A. Furtado, C. Krause, \& K. C. B. França (Eds.), Território metropolitano, políticas municipais: por soluções conjuntas de problemas urbanos no âmbito metropolitano (p. 53-82). Brasília: IPEA.

Tomio, F. R. D. L. (2002). A criação de municípios após a Constituição de 1988. Revista Brasileira de Ciências Sociais, 17(48), 62-89. http://dx.doi.org/10.1590/ S0102-69092002000100006.

Recebido: Out. 20, 2016

Aprovado: Jun. 14, 2017 